\title{
Prevalence of overuse of short-acting beta- 2 agonists (SABA) and associated factors among patients with asthma in Germany
}

\author{
Heinrich Worth ${ }^{1 *}$, Carl-Peter Criée ${ }^{2}$, Claus F. Vogelmeier ${ }^{3}$, Peter Kardos ${ }^{4}$, Eva-Maria Becker ${ }^{5}$, Karel Kostev ${ }^{5}$, \\ Ingo Mokros ${ }^{6}$ and Andrea Schneider ${ }^{6}$
}

\begin{abstract}
Background: Overuse of short-acting beta-2 agonists (SABA), which do not treat the underlying inflammation of asthma, is linked to poor clinical outcomes such as increased exacerbation risk. This study, as part of the SABINA program, estimated the prevalence of SABA overuse and associated variables in outpatients in Germany.

Methods: This retrospective study used anonymized electronic healthcare data from the Disease Analyzer database (IQVIA). A total of 15,640 patients aged $\geq 12$ years with asthma who received $\geq 1$ SABA prescription(s) between July 2017 and June 2018 in 924 general physician and 22 pneumologist (PN) practices were included. SABA overuse was defined as $\geq 3$ prescribed inhalers ( 200 puffs each) during the study period. The associations between SABA overuse and physician specialty, Global Initiative for Asthma (GINA) steps (based on asthma medications), age, sex, and inhaled corticosteroid (ICS)/long-acting beta agonist (LABA) use were estimated using multivariable regression for patients with probable moderate (GINA step 2) and probable severe (GINA steps 3-5) asthma.
\end{abstract}

Results: Annually, $36 \%$ of all patients (GINA steps $1-5$ ) in general and $38 \%$ in PN practices received $\geq 3$ SABA inhalers. The risk of SABA overuse was $14 \%$ higher in patients treated by a general practitioner vs. a PN; $34 \%$ and $85 \%$ higher in GINA steps 4 and 5, respectively, vs. GINA step 3; and 40\% higher in male vs. female patients.

Conclusions: SABA overuse is prevalent among patients with asthma across all GINA steps in Germany, which may indicate suboptimal asthma control. Further studies are needed to investigate the reasons behind SABA overuse.

Keywords: Asthma, Short-acting beta agonists, Overuse, GINA, Risk factors, Germany

\section{Background}

The lifetime prevalence of asthma in adults in Germany is approximately $6-9 \%[1,2]$. The prevalence varies considerably between federal states in Germany and is known to be higher in adult women than in men and in people with a low level of education [2]. Severe asthma is present, by definition, when adequate control of asthma cannot be achieved by high-dose treatment with inhaled

\footnotetext{
*Correspondence: h.worth49@gmail.com

${ }^{1}$ Facharzt Forum Fürth, Bahnhofplatz 6, 90762 Fürth, Germany

Full list of author information is available at the end of the article
}

corticosteroids (ICS) and additional controllers (inhaled long-acting beta- 2 agonists [LABA], montelukast, and/or theophylline) and/or by oral corticosteroid treatment or if efficacy is lost when treatment is reduced [3].

One of the known problems in asthma patient care is the overuse of inhaled short-acting beta- 2 agonists (SABA) $[4,5]$. Overuse of reliever inhalers is a common problem in people with asthma, which was highlighted by the Medical Expenditure Panel Survey finding that $15 \%$ of the asthma population in the United States used more than one reliever inhaler per month [6]. Based on existing studies, it can be concluded that opinions on original author(s) and the source, provide a link to the Creative Commons licence, and indicate if changes were made. The images or other third party material in this article are included in the article's Creative Commons licence, unless indicated otherwise in a credit line to the material. If material is not included in the article's Creative Commons licence and your intended use is not permitted by statutory regulation or exceeds the permitted use, you will need to obtain permission directly from the copyright holder. To view a copy of this licence, visit http://creativecommons.org/licenses/by/4.0/. The Creative Commons Public Domain Dedication waiver (http://creativeco mmons.org/publicdomain/zero/1.0/) applies to the data made available in this article, unless otherwise stated in a credit line to the data. 
the duration of time needed to determine SABA overuse varies from daily and weekly doses to a monthly inhaler count. According to a Global Initiative for Asthma (GINA) report, the use of a reliever inhaler for symptoms more than twice per week in the past 4 weeks is classified as partly controlled asthma. If symptoms and activity limitation due to asthma are present nevertheless, it is classified as uncontrolled asthma [7].

The inclusion of reliever inhaler use in the assessment of asthma control in adults is based on the evidence that overuse of SABA medication is associated with poor symptom control [8], increased risk of exacerbations [9, $10]$, and death from asthma $[11,12]$.

Factors associated with inappropriate or excessive use of SABA include male sex, low socioeconomic status, and low continuity of care. However, knowledge of these factors is based on studies performed in countries other than Germany [13].

There are limited data on the prevalence of SABA overuse in Germany, and especially on the factors associated with it [4]. For example, Janson et al. investigated the prevalence of SABA overuse based on the number of canisters; however, these canisters could contain different number of puffs [4]. Given the large number of patients with asthma, the high prevalence of SABA overuse, and the substantial risk of complications associated with this overuse, it is important to use available German epidemiological databases to analyze SABA overuse, comparing different definitions within the same data source.

The SABA use IN Asthma (SABINA) program, which has been previously described [4], aims to describe asthma treatment prescription patterns, the extent of SABA overuse, and its impact on asthma-related clinical outcomes through a series of large observational cohort studies in different countries. This study, which is part of the SABINA program, aims to evaluate the prevalence of SABA overuse and factors associated with this overuse in German outpatient care.

\section{Methods \\ Database}

This study is based on data from the Disease Analyzer database (IQVIA), which compiles drug prescriptions, diagnoses, and basic medical and demographic data obtained directly and anonymously from computer systems used in the practices of general practitioners (GPs) and specialists. Diagnoses (International Classification of Diseases, 10th Revision [ICD-10]), prescriptions (Anatomical Therapeutic Chemical [ATC] classification system), and the quality of reported data were monitored by IQVIA based on multiple criteria (e.g., completeness of documentation, linkage between diagnoses and prescriptions) [14]. In Germany, the sampling methods used for the selection of physicians' practices were appropriate for obtaining a representative database of general and specialized practices [14]. Finally, this database had already been used in studies focusing on asthma [15] and drug utilization [16, 17].

\section{Study population}

This cross-sectional study included outpatients aged $\geq 12$ years with an asthma diagnosis (ICD-10: J45, J46) who had received $\geq 1$ SABA (European Pharmaceutical Market Research Association [EphMRA] ATC: R03A4) prescription(s) between July 2017 and June 2018 in 924 general physician and 22 pneumologist (PN) practices. Furthermore, patients had to fulfill the observability criterion of having had at least two physician visits (not necessarily asthma-related) during the study period. Patients with chronic obstructive pulmonary disease in addition to their asthma diagnosis were excluded from the study (Fig. 1).

\section{Study outcome}

The main outcome of this study was the prevalence of SABA overuse/increased use and assessment of its association with different factors. Based on GINA, SABA overuse was defined as $\geq 3$ prescribed inhalers $(\sim 200$ puffs each) during the study period. The term "overuse" was appropriated from the GINA report; however, it should be noted that in GINA step 5 , the use of $\geq 3$ prescribed inhalers is considered as increased use but not overuse. The prevalence of SABA overuse was estimated as the proportion of patients receiving $\geq 3$ prescribed inhalers out of all patients with asthma included in the study. The prevalence was calculated for the total number of patients as well as stratified by age group, sex, GINA step, physician specialty, ICS with/without LABA (EphMRA ATC: R03A3, R03D1, R03F1) use, defined comorbidities (upper respiratory infections, diabetes mellitus, thyroid gland disorders, hypertension, lipid metabolism disorders, depression), co-therapies which are known to be associated with an increased risk for bronchospasm (non-steroidal anti-inflammatory drugs [NSAIDs] [ATC: $\mathrm{M} 01 \mathrm{~A}$ ], aspirin [ATC: B01C1], and angiotensin-converting enzyme [ACE] inhibitors [ATC: C09A, C09B]) [1820]. Moreover, the associations of these variables with SABA overuse were investigated.

\section{Statistical analyses}

SABA overuse analyses were of a descriptive nature. The associations between SABA overuse and physician specialty, GINA step (based on prescribed asthma medications), age, and sex were estimated using multivariable regression. Co-diagnoses and co-therapies were also included in the model. ICS/LABA use was 


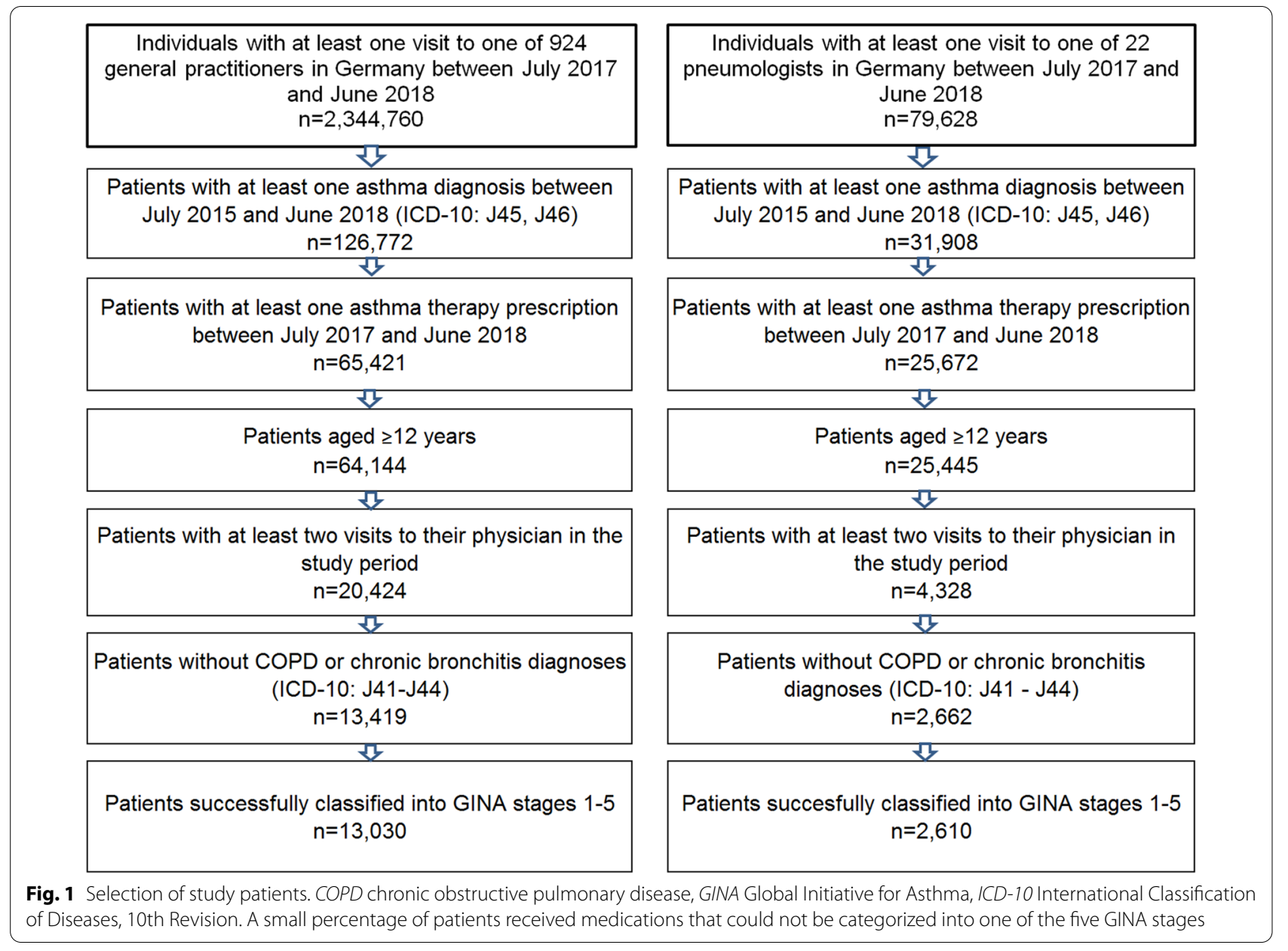

not included in the logistic regression because the proportion of patients with ICS/LABA use was a part of the GINA definition, and $95 \%$ of patients at GINA steps 3-5 were treated with ICS/LABA. $P$ values $<0.05$ were considered statistically significant. All analyses were carried out using SAS version 9.4 (SAS Institute, Cary, $\mathrm{NC}$ ).

\section{Results}

\section{Baseline characteristics of study patients}

A total of 15,640 patients (13,030 GP patients and 2,610 PN patients) with $\geq 1$ SABA prescription(s) during the study period were included in the study. The mean (standard deviation) age of patients was 49 (18) years for GP patients and 56 (16) years for PN patients. The proportion of female patients was $59 \%$ in general practices and $68 \%$ in PN practices, while $21 \%$ of GP patients and $49 \%$ of PN patients were classified as being at GINA treatment step 4 or 5 (Table 1 ).

\section{Prevalence of SABA overuse}

Annually, 36\% of all GP patients (GINA steps 1-5) and $38 \%$ of all $\mathrm{PN}$ patients received $\geq 3$ SABA inhalers. Over the same period, $7 \%$ of GP patients and $3 \%$ of PN patients received $\geq 12$ inhalers (Fig. 2). The proportion of patients with SABA overuse increased with GINA step ( $52 \%$ seen by GPs and $54 \%$ seen by PNs). Moreover, this proportion was higher in men and in patients who received ICS/LABA therapy (Fig. 3).

\section{Variables associated with SABA overuse}

Figure 4 displays the results of the multivariable logistic regression. The risk of SABA overuse/increased use was $14 \%$ higher in patients treated by a GP vs. a PN; $34 \%$ and $85 \%$ higher in GINA steps 4 and 5, respectively, vs. GINA step 3; and $40 \%$ higher in male vs. female patients. No significant effects were observed for other variables. 
Table 1 Baseline characteristics of asthma patients under general physician and pneumologist care in Germany

\begin{tabular}{lll}
\hline Variable & GPs & PNs \\
\hline N & 13,030 & 2610 \\
GINA classes & & \\
GINA 1 & $5426(42)$ & $99(4)$ \\
GINA 2 & $841(6)$ & $165(6)$ \\
GINA 3 & $4012(31)$ & $1065(41)$ \\
GINA 4 & $2410(18)$ & $1064(41)$ \\
GINA 5 & $341(3)$ & $217(8)$ \\
Age (years) & & $56(16)$ \\
Mean (SD) & $49(18)$ & $29(1)$ \\
12 to $<18$ & $244(2)$ & $1780(68)$ \\
18 to 65 years & $10,330(77)$ & $801(31)$ \\
$>65$ years & $2456(19)$ & $1770(68)$ \\
Sex & & $840(32)$ \\
Female & $7665(59)$ & $2461(94)$ \\
Male & $5364(41)$ & $149(6)$ \\
ICS/LABA prescriptions & & \\
Yes & $7227(55)$ & $5803(45)$
\end{tabular}

GINA Global Initiative for Asthma, GP general practitioner, ICS inhaled corticosteroid, $L A B A$ long-acting beta agonist, $P N$ pneumologist, $S D$ standard deviation

Data are presented as $\mathrm{n}(\%)$ unless stated otherwise

\section{Discussion}

\section{Summary of main findings}

This German retrospective study of 15,640 patients with asthma showed that the proportion of patients with SABA overuse/increased use was very high, especially among patients treated by GPs, patients classified as being at GINA step 4 or 5 , and male patients.

\section{Prevalence of SABA overuse}

In the multicountry study based on five European countries including Germany, Janson et al. investigated the current burden of SABA use among patients with asthma as part of the SABINA program [4]. They reported that the prevalence of SABA overuse, defined as $\geq 3$ inhalers per year, was $16 \%$ in Germany [4]. In our study, the prevalence was $36 \%$ in patients seen by GPs and $38 \%$ in patients seen by PNs. The main difference in the methodology between the study by Janson et al. and the present study was the required observation time. In the study by Janson et al., patients had to be followed-up for at least 12 months before and after study entry, whereas in our study, patients had to fulfill the observability criterion of having had at least two visits with their physician during the study period. Moreover, the SABINA study included patients treated by GPs only, and the present study additionally contained data of patients treated by PNs.

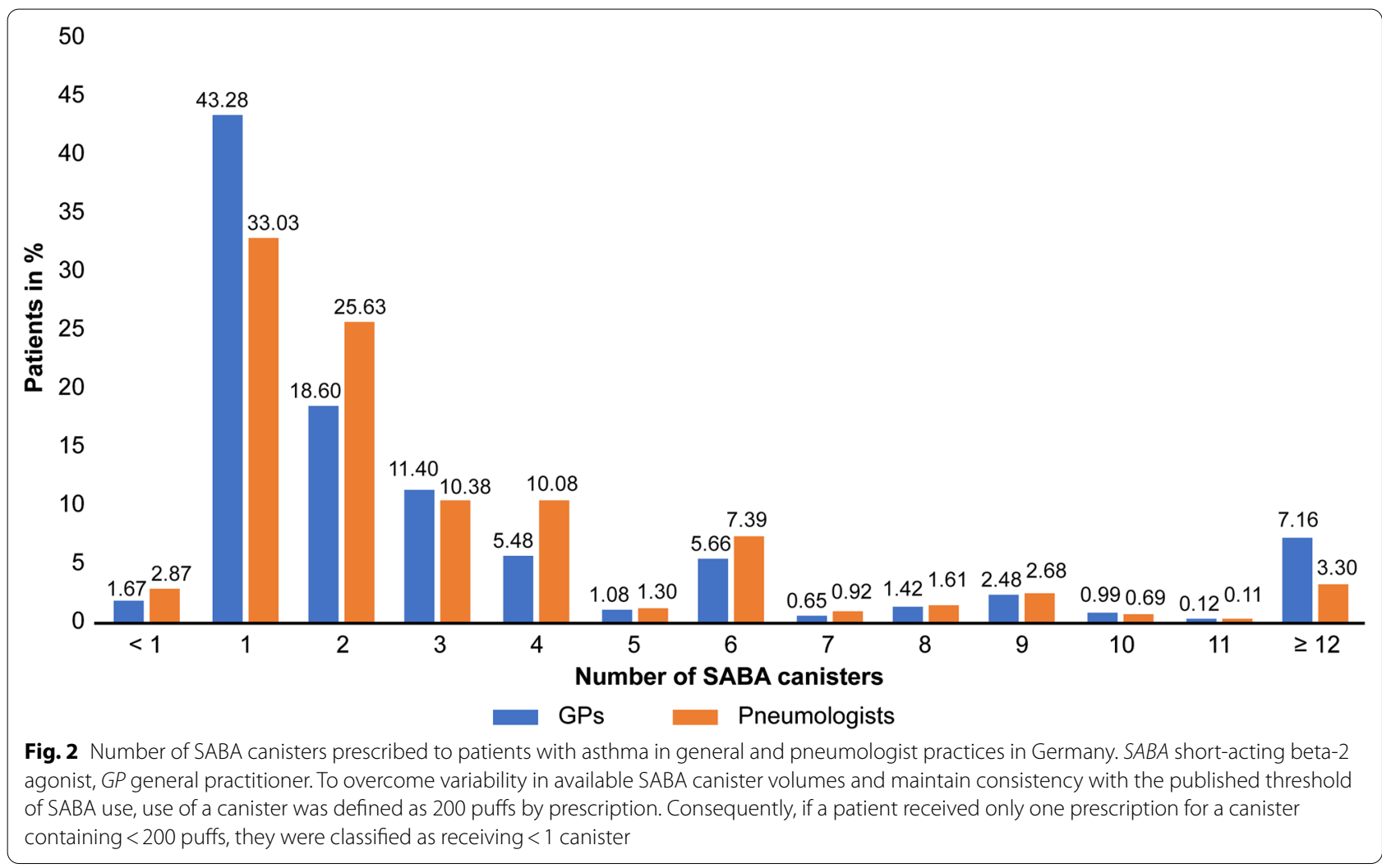




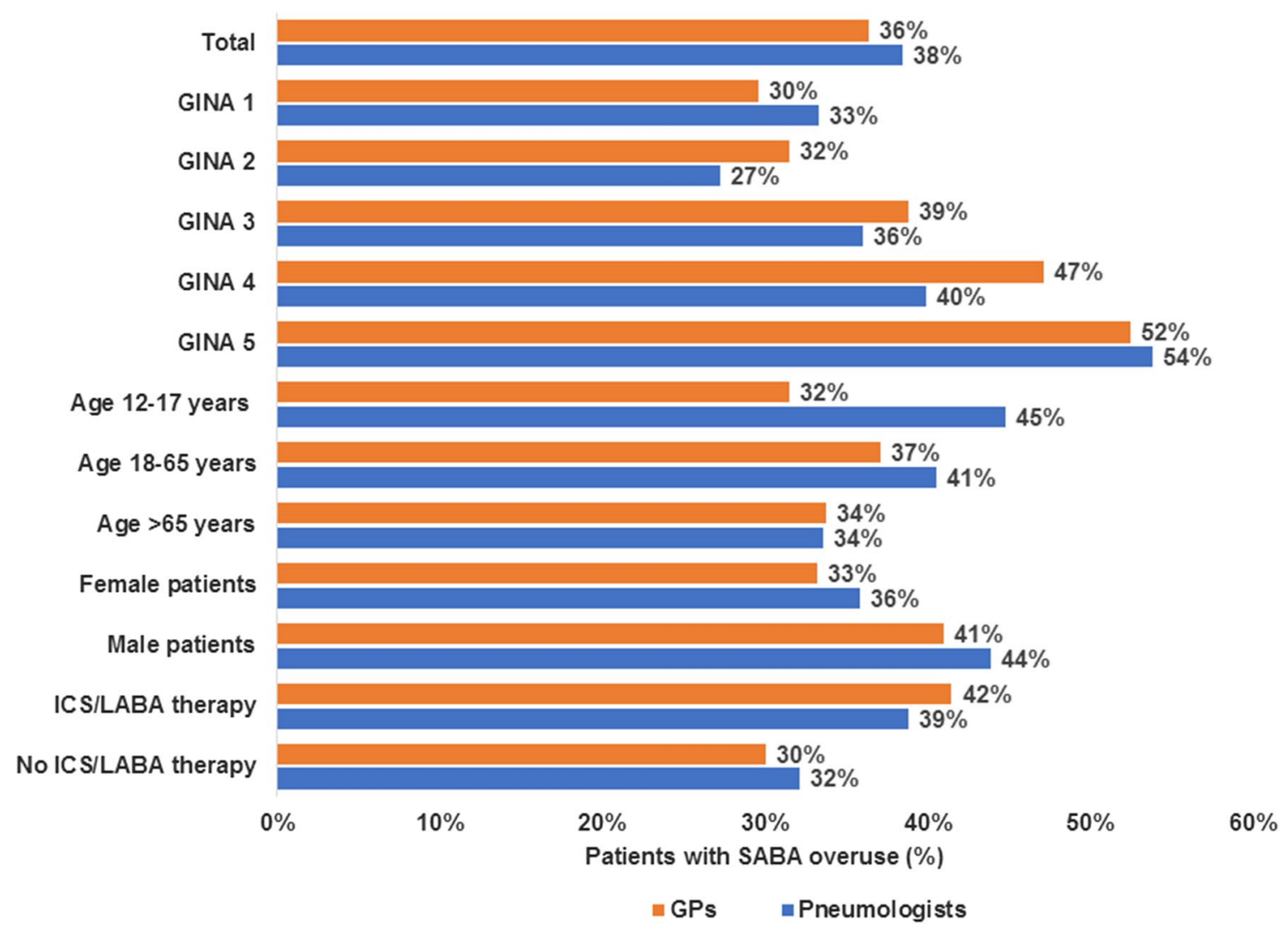

Fig. 3 Prevalence of SABA overuse in patients treated in general and pneumologist practices in Germany. GINA Global Initiative for Asthma, GP general practitioner, ICS inhaled corticosteroid, LABA long-acting beta agonist, SABA short-acting beta-2 agonist

GINA 1 vs. GINA 3

GINA 2 vs. GINA 3

GINA 4 vs. GINA 3

GINA 5 vs. GINA 3

AGE 18-65 vs. AGE 12-17

AGE >65 vs. AGE 12-17

GPs vs. PNEUMOLOGISTS

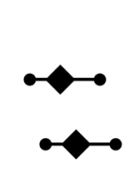

$\mathrm{HR}=0.65$ [95\% Cl: 0.60-0.71]; $p<0.001$

$\mathrm{HR}=0.72$ [95\% Cl: $0.63-0.84] ; p<0.001$

$\mathrm{HR}=1.34$ [95\% Cl: 1.23-1.47]; $p<0.001$

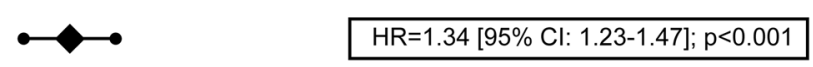

$\mathrm{HR}=1.85[95 \% \mathrm{Cl}: 1.55-2.20] ; \mathrm{p}<0.001$

$\mathrm{HR}=1.22$ [95\% Cl: 0.94-1.58]; $\mathrm{p}=0.127$

$\mathrm{HR}=1.02$ [95\% Cl: 0.78-1.33]; $p=0.908$

MEN vs. WOMEN

\begin{tabular}{cccc}
\hline 0.0 & 0.5 & 1.0 & 1.5 \\
& & Odds Ratio $(95 \% \mathrm{Cl})$
\end{tabular}

Fig. 4 Variables associated with SABA overuse (multivariable logistic regression). Cl confidence interval, GINA Global Initiative for Asthma, HR hazard ratio, GP general practitioner, SABA short-acting beta-2 agonist 
Our findings are in line with the results of other studies using the same definition of SABA overuse. In a large study from Poland based on pharmacy prescription records of more than 90,000 adult patients, SABA overuse was observed in $29-37 \%$ of patients [21]. In another study including approximately 16,000 patients in France, $28 \%$ of patients with asthma overused SABA therapy [22].

\section{Variables associated with SABA overuse}

The proportion of patients with SABA overuse was higher in patients at GINA steps 3-5 (patients with probable severe asthma) compared with those at GINA step 1 or 2 (patients with probable mild asthma), showing poor asthma control in patients with severe asthma. This poor control was observed despite patients receiving ICS/LABA. At GINA steps 3-5, the risk of SABA overuse/increased use was even higher in patients using ICS/ LABA. Patients treated by GPs were at a higher risk of overusing SABA compared with those treated by PNs. This finding could be attributed to non-familiarity of GPs with the updated GINA recommendations, which could have resulted in continued high prescribing of SABA [23]. Educational initiatives targeting physicians, pharmacists, and patients are required to align clinical practices with current treatment recommendations. PNs are more likely to prescribe SABA in line with therapy guidelines compared with GPs, given the PNs' greater experience with asthma treatment. However, PNs may tend to treat more severe cases, which require earlier ICS/LABA and more SABA therapy.

In this study, SABA overuse was higher in men than in women. Several studies have investigated gender differences in asthma diagnosis and severity. Although female sex was shown to be an independent risk factor for severe asthma exacerbation among adults, [24], men exhibited lower therapeutic adherence with asthma therapy than women [24-26]. Our results are in line with the findings of Tavakoli et al. who reported that male sex was associated with a 1.49 -fold higher likelihood of inappropriate SABA use [13].

\section{Consequences of SABA overuse}

Although SABA are as-needed inhaled medications, they often appear to be used as long-term medications for asthma control, even though this is not in accordance with the guidelines [3]. Different complications of SABA overuse have been described in older and newer studies. A long-term study in New Zealand showed that regular use of SABA four times a day was associated with a deterioration in asthma control [27]. In a large Swedish population-based study, also part of the SABINA II program, which included data of more than 365,000 patients, SABA overuse was associated with an increased risk of asthma exacerbation and mortality [11]. The Swedish researchers used the same SABA overuse definition, that is, the use of $\geq 3$ SABA inhalers within a 1-year period [11]. In a real-world, cross-sectional observational study by Azzi et al. SABA overusers were more likely to have moderate to severe nasal symptoms, tachycardia, vasodilation, transient hypoxemia, hyperglycemia, hypokalemia, and tremor [28]; a diagnosis of depression [5]; and an increased risk of emergency department visit or hospitalization $[29,30]$.

\section{Clinical implications}

Our findings indicate that a high proportion of patients with asthma overuse SABA in Germany. Based on similar studies, this overuse probably carries a risk of adverse outcomes. There is no valid information on the reasons for the overuse of SABA. Both patients and physicians can have an impact on this. Physicians should eliminate SABA monotherapy and explain the consequences of SABA overuse to patients. Further, physicians, especially GPs, should ensure adherence of their patients to ICS treatment, considering continued ICS therapy can reduce the overuse of SABA. Asthma education programs for patients should pay special attention to regulated SABA use. Pharmacists play an important role in the care of patients with asthma and they should explain the appropriate use of SABA to patients who collect such medication from pharmacies.

\section{Strengths and limitations}

The strengths of this study include the number of outpatients available for analysis and the use of real-world data, which allowed an unbiased exposure assessment (no recall bias) in a German cohort of patients with asthma for the first time. Moreover, we used a standardized definition of a SABA canister ( $\sim 200$ puffs/canister) to enable a more exact estimation of SABA overuse.

Retrospective primary care database analyses, however, are generally limited by the validity and completeness of the data they contain. First, diagnoses and comorbidities relied solely on ICD codes used in general physician and pneumologist practices, and no information was available regarding the procedure used to diagnose asthma. Asthma severity stages were established using GINA treatment steps according to the prescriptions of asthma medications because no documented information on the diagnosis of asthma severity or the level of asthma control was available; however, it is uncertain if physicians treated patients in line with these recommendations.

Second, data on the socioeconomic status (education and income) and lifestyle-related risk factors (smoking, alcohol use, and physical activity) of patients were lacking. Third, information from hospitals was not available. 
Fourth, receiving a prescription does not necessarily mean that the prescription was filled and used by the patient. There is a possibility that patients who received a prescription did not take the medication. In addition, information on whether patients received asthma education or written asthma action plans and their level of adherence to prescribed therapies was not captured in the study. Fifth, in the German healthcare system, a patient can receive prescriptions for asthma treatment from several doctors, for example, from both a GP and a PN; however, in this database, usually only one doctor's prescriptions are captured. Sixth, no information on patients' asthma training was available. Seventh, no separation of ICS/LABA therapy into reliever and controller was possible. Finally, the study was conducted in Germany, and its findings may not be extrapolated to populations in other countries due to differences in national health systems and the availability of SABA medications.

\section{Conclusions}

In Germany, similar to other countries in the SABINA program, SABA overuse is prevalent among patients with asthma across all GINA steps, which may indicate suboptimal asthma control, suboptimal treatment practice, and suboptimal adherence to prescribed medication. Although, some original studies $[4,11]$, and a review article [31] have dealt with the problem of SABA overuse, further studies are needed to investigate the reasons behind the overuse of SABA.

\section{Abbreviations}

ATC: Anatomical Therapeutic Chemical; EphMRA: European Pharmaceutical Market Research Association; GINA: Global Initiative for Asthma; GP: General practitioner; ICD-10: International Classification of Diseases, 10th Revision; ICS: Inhaled corticosteroid; LABA: Long-acting beta agonist; PN: Pneumologist; SABA: Short-acting beta-2 agonist; SABINA: SABA use IN Asthma.

\section{Acknowledgements}

Not applicable.

\section{Authors' contributions}

$\mathrm{E}-\mathrm{MB}$ and $\mathrm{KK}$ analyzed and interpreted the patient data. KK managed the literature searches and wrote the first draft of the manuscript. HW, C-PC, CFV, PK, IM, and AS contributed to the design of the study and reviewed the manuscript. All authors read and approved the final manuscript.

\section{Funding}

This study was funded by AstraZeneca.

\section{Availability of data and materials}

The datasets generated during and/or analyzed during the current study are not publicly available due to data protection rules but are available from the corresponding author on reasonable request.

\section{Declarations}

Ethics approval and consent to participate

German law allows the use of anonymous electronic medical records for research purposes under certain conditions. According to this legislation, it is not necessary to obtain informed consent from patients or approval from a medical ethics committee for this type of observational study that contains no directly identifiable data. Because patients were only queried as aggregates and no protected health information was available for queries, no institutional review board approval was required for the use of this database or the completion of this study.

\section{Consent for publication}

Not applicable.

\section{Competing interests}

IM and AS are employees of AstraZeneca. E-MB and KK are employees of IQVIA. PK reports personal fees from Novartis, AstraZeneca, Boehringer Ingelheim, Chiesi, GlaxoSmithKline, Menarini, and Takeda, all of which are outside the submitted work. CFV reports personal fees from Almirall, Cipla, Berlin-Chemie/Menarini, CSL Behring, and Teva, grants and personal fees from AstraZeneca, Boehringer Ingelheim, Chiesi, GlaxoSmithKline, Grifols, Mundipharma, Novartis, and Takeda, and grants from the German Federal Ministry of Education and Research (BMBF) Competence Network Asthma and COPD (AsCoNet), Bayer Schering Pharma AG, MSD, and Pfizer, all of which are outside the submitted work. HW reports personal fees from AstraZeneca, Boehringer Ingelheim, Chiesi, GlaxoSmithKline, Klosterfrau, Menarini, Novartis, Omron, and Takeda, all of which are outside the submitted work. C-PC reports personal fees from AstraZeneca, Boehringer Ingelheim, Chiesi, GlaxoSmithKline, Klosterfrau, Menarini, Novartis, Omron, Sanofi, and Takeda, all of which are outside the submitted work.

\section{Author details}

${ }^{1}$ Facharzt Forum Fürth, Bahnhofplatz 6, 90762 Fürth, Germany. ${ }^{2}$ Evangelisches Krankenhaus Göttingen-Weende, Göttingen, Germany. ${ }^{3}$ Department of Medicine, Pulmonary and Critical Care Medicine, University Medical Center Giessen and Marburg, Philipps-Universität Marburg, Marburg, Germany. ${ }^{4}$ Lungenpraxis am Maingau Krankenhaus, Frankfurt am Main, Germany. ${ }^{5}$ IQVIA, Frankfurt am Main, Germany. ${ }^{6}$ AstraZeneca GmbH, Wedel, Germany.

Received: 11 September 2020 Accepted: 31 March 2021

Published online: 16 April 2021

\section{References}

1. Bergmann KC, Heinrich J, Niemann H. Current status of allergy prevalence in Germany. Allergo J Int. 2016;25:6-10.

2. Steppuhn H, Kuhnert R, Scheidt-Nave C. 12-month prevalence of asthma among adults in Germany. J Health Monitor. 2017;2:34-42.

3. Chung KF, Wenzel SE, Brozek JL, Bush A, Castro M, Sterk PJ, et al. International ERS/ATS guidelines on definition, evaluation and treatment of severe asthma. Eur Respir J. 2014;43:343-73.

4. Janson C, Menzies-Gow A, Nan C, Nuevo J, Papi A, Quint JK, et al. SABINA: an overview of short-acting $\beta 2$-agonist use in asthma in European countries. Adv Ther. 2020;37:1124-35.

5. Azzi EA, Kritikos V, Peters MJ, Price DB, Srour P, Cvetkovski B, et al. Understanding reliever overuse in patients purchasing over-the-counter shortacting beta2 agonists: an Australian community pharmacy-based survey. BMJ Open. 2019;9:e028995.

6. Slejko JF, Ghushchyan VH, Sucher B, Globe DR, Lin SL, Globe G, et al. Asthma control in the United States, 2008-2010: indicators of poor asthma control. J Allergy Clin Immunol. 2014;133:1579-87.

7. Global Initiative for Asthma (GINA). GINA Report, Global Strategy for Asthma Management and Prevention; 2014. http://www.ginasthma.com. Accessed 10 Oct 2018.

8. Patel M, Pilcher J, Munro C, Hosking A, Pritchard A, Shaw D, SMART Study Group, et al. Short-acting $\beta$-agonist use as a marker of current asthma control. J Allergy Clin Immunol Pract. 2013;1:370-7.

9. Bateman ED, Buhl R, O'Byrne PM, Humbert M, Reddel HK, Sears MR, et al. Development and validation of a novel risk score for asthma exacerbations: the risk score for exacerbations. J Allergy Clin Immunol. 2015:135:1457-64.

10. Patel M, Pilcher J, Reddel HK, Pritchard A, Corin A, Helm C, SMART Study Group, et al. Metrics of salbutamol use as predictors of future adverse outcomes in asthma. Clin Exp Allergy. 2013;43:1144-51. 
11. Nwaru BI, Ekström M, Hasvold P, Wiklund F, Telg G, Janson C. Overuse of short-acting $\beta 2$-agonists in asthma is associated with increased risk of exacerbation and mortality: a nationwide cohort study of the global SABINA programme. Eur Respir J. 2020;55:1901872.

12. Suissa $S$, Blais $L$, Ernst P. Patterns of increasing beta-agonist use and the risk of fatal or near-fatal asthma. Eur Respir J. 1994;7:1602-9.

13. Tavakoli H, FitzGerald JM, Lynd LD, Sadatsafavi M. Predictors of inappropriate and excessive use of reliever medications in asthma: a 16-year population-based study. BMC Pulm Med. 2018;18:33.

14. Rathmann W, Bongaerts B, Carius HJ, Kruppert $Y$, Kostev K. Basic characteristics and representativeness of the German Disease Analyzer database. Int J Clin Pharmacol Ther. 2018;56:459-66.

15. Jacob L, Keil T, Kostev K. Comorbid disorders associated with asthma in children in Germany - national analysis of pediatric primary care data. Pediatr Allergy Immunol. 2016;27:86.

16. Kostev K, Von Vultée C, Usinger DM, Reese JP. Tramadol prescription patterns in patients followed by general practitioners and orthopedists in Germany in the year 2015. Postgrad Med. 2018;130:37-41.

17. Mell T, Jacob L, Fuhr I, Dick S, Rapp MA, Kostev K. Patterns of benzodiazepine prescribing by neuropsychiatrists and general practitioners for elderly patients in Germany in 2014. Int J Clin Pharmacol Ther. 2017:55:466-71.

18. Lo PC, Tsai YT, Lin SK, Lai JN. Risk of asthma exacerbation associated with nonsteroidal anti-inflammatory drugs in childhood asthma: a nationwide population-based cohort study in Taiwan. Medicine (Baltimore). 2016;95:e5109.

19. Jenkins C, Costello J, Hodge L. Systematic review of prevalence of aspirin induced asthma and its implications for clinical practice. BMJ. 2004;328:434

20. Christiansen SC, Zuraw BL. Treatment of hypertension in patients with asthma. N Engl J Med. 2019:381:1046-57.

21. Kupczyk M, Barg W, Bochenek G, et al. Late breaking abstract-overprescription of short-acting beta2-agonists in asthma management? Pharmacy reports from 91,673 patients in Poland. Eur Respir J. 2019;54(Suppl 63):OA2107.
22. Raherison-Semjen C, Izadifar A, Russier M, Rolland C, Aubert JP, Sellami R, et al. Late breaking abstract-asthma prevalence and management in adults in France in 2018: ASTHMAPOP survey. Eur Respir J. 2018;52(Suppl 62):OA292.

23. Chapman KR, Hinds D, Pizza P, Raherison C, Gibbs M, Greulich T, et al. Physician perspectives on the burden and management of asthma in six countries: The Global Asthma Physician Survey (GAPS). BMC Pulm Med. 2017; 17:153.

24. McCallister JW, Mastronarde JG. Sex differences in asthma. J Asthma. 2008;45:853-61.

25. Lindner PS, Lindner AJ. Gender differences in asthma inhaler compliance. Conn Med. 2014;78:207-10.

26. Sundberg R, Torén K, Franklin KA, Gislason T, Omenaas E, Svanes C, et al. Asthma in men and women: treatment adherence, anxiety, and quality of sleep. Respir Med. 2010;104:337-44.

27. Pearce N, Grainger J, Atkinson M, Crane J, Burgess C, Culling C, et al. Casecontrol study of prescribed fenoterol and death from asthma in New Zealand, 1977-81. Thorax. 1990:45:170-5.

28. Fan VS, Gylys-Colwell I, Locke E, Sumino K, Nguyen HQ, Thomas RM, et al. Overuse of short-acting beta-agonist bronchodilators in COPD during periods of clinical stability. Respir Med. 2016;116:100-6.

29. Butz AM, Ogborn J, Mudd S, Ballreich J, Tsoukleris M, Kub J, et al. Factors associated with high short-acting $\beta 2$-agonist use in urban children with asthma. Ann Allergy Asthma Immunol. 2015;114:385-92.

30. Stanford RH, Shah MB, D'Souza AO, Dhamane AD, Schatz M. Short-acting $\beta$-agonist use and its ability to predict future asthma-related outcomes. Ann Allergy Asthma Immunol. 2012;109:403-7.

31. Amin S, Soliman M, Mclvor A, Cave A, Cabrera C. Usage patterns of shortacting $\beta 2$-agonists and inhaled corticosteroids in asthma: a targeted literature review. J Allergy Clin Immunol Pract. 2020;8:2556-64.

\section{Publisher's Note}

Springer Nature remains neutral with regard to jurisdictional claims in published maps and institutional affiliations.
Ready to submit your research? Choose BMC and benefit from:

- fast, convenient online submission

- thorough peer review by experienced researchers in your field

- rapid publication on acceptance

- support for research data, including large and complex data types

- gold Open Access which fosters wider collaboration and increased citations

- maximum visibility for your research: over $100 \mathrm{M}$ website views per year

At BMC, research is always in progress.

Learn more biomedcentral.com/submissions 